\title{
Hermenêutica-fenomenológica e compreensão nas ciências sociais
}

\author{
Paulo César Alves* \\ Míriam Cristina Rabelo** \\ lara Maria Souza***
}

Resumo: O presente texto tem por objetivo identificar os pressupostos subjacentes na ideia de compreensão para as teorias sociais fundamentadas pelos pressupostos hermenêutico-fenomenológicos. Inicialmente, procura caracterizar criticamente o significado de subjetividade e objetividade herdado do lluminismo e do Romantismo, argumentando que ambas presumem as mesmas concepções de tradição, embora com sinais invertidos. Em seguida, inspirando-se em Gadamer e Heidegger, o texto discute a proposta da hermenêutica-fenomenológica contemporânea para concluir que compreensão tem, em "si mesma", a estrutura de uma experiência. Assim, compreender significa, em última instância, empreender um diálogo com o "outro", através de uma mediação histórica - e, portanto, mutável - presente no encontro entre horizontes distintos.

Palavras-chave: hermenêutica; compreensão; fenomenologia; teoria social.

\section{Introdução}

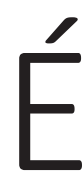

corrente a ideia de que as sociologias compreensivas, por lidarem com "construções de segundo grau" - interpretações elaboradas pelo pesquisador acerca de interpretações produzidas pelos atores sociais em sua vida cotidiana -, estão enredadas na armadilha do psicologismo, do subjetivismo e do meramente contextual. O trabalho do sociólogo, nesse caso, seria meramente (re)descrever - em uma linguagem mais ou menos complexa - aquilo que foi feito ou dito pelos agentes, enfatizando suas motivações e interesses. Esse pressuposto está subjacente a duas posições analíticas. A primeira considera que as sociologias compreensivas não ultrapassam aquilo que está simplesmente presente aos olhos do observador ou à consciência do ouvinte. A segunda parte do princípio que a compreensão proposta por essas correntes sociológicas é um complemento às explicações macrossociais, pois a análise das subjetividades deve acompanhar as interpretações de cunho mais objetivista. Ambas posições estão de acordo que o campo próprio da compreensão é a subjetividade.

A identificação do objeto da compreensão com a subjetividade remonta a uma longa controvérsia teórica sobre os fundamentos metodológicos considerados adequados às ciências sociais. Tal controvérsia pode ser brevemente resumida nos seguintes termos: por um lado, há aqueles que argumentam que as ciências sociais devem seguir

\author{
* Professor titular \\ do Departamento \\ de Sociologia \\ da Universidade \\ Federal da Bahia, \\ pós-doutorado nas \\ Universidades de \\ Toronto (Canadá) \\ e St. Andrews \\ (Escócia), bolsista \\ de produtividade \\ pelo CNPq. \\ <paulo.c.alves@uol. \\ com.br> \\ ** Professora do \\ Departamento \\ de Sociologia \\ da Universidade \\ Federal da Bahia, \\ pós-doutorado nas \\ Universidades de \\ Toronto (Canadá) \\ e Aberdeen \\ (Escócia), bolsista de \\ produtividade pelo \\ CNPq. \\ <mcmrabelo@uol. \\ com.br>.

*** Professora
do Departamento
de Sociologia
da Universidade
Federal da Bahia,
pós-doutorado na
Universidade Federal
do Rio de Janeiro.
<iara-souza@uol.
com.br>. \\ *** Professora \\ do Departamento \\ de Sociologia \\ da Universidade \\ Federal da Bahia, \\ pós-doutorado na \\ Universidade Federa \\ <iara-souza@uol. \\ com.br>
}


1. O termo "idade de ouro", cunhado por Picó (2003), designa o tipo de sociologia desenvolvida entre as décadas de 1940 e 1970. Foi nesse período que se deu a reconstrução das sociologias nacionais e sua maior institucionalização nas universidades, particularmente nos Estados Unidos, através dos aportes teóricometodológicos de cientistas sociais como Parsons, Merton, Lazarsfeld, Lockwood, Dahrendorf, Friedmann, König e Adorno, entre outros (cf. Friedrich, 2001; Platt, 1996; Hinkle, 1994; Arnove, 1982). os princípios explicativos das ciências naturais, enquanto outros clamam pela diferença entre elas, tanto em relação aos seus objetos como em relação aos seus métodos. A explicação e a compreensão, nesse último caso, constituiriam atos gnoseológicos distintos para a apreensão dos objetos naturais e culturais, respectivamente. Essa controvérsia foi inicialmente formulada pela tradição Geisteswissenschaftliche (ciências do espírito) presente nas obras de Dilthey, Simmel e Weber, entre outros.

Entre a Segunda Guerra e a década de 1970, período que Picó (2003) denominou de "época dourada" da sociologia, ${ }^{1}$ os fundamentos epistemológicos das "ciências do espírito" foram usualmente criticados como modalidade de idealismo: por negligenciarem a importância dos "fatores reais e materiais" da vida social; por seu caráter contemplativo e descritivo; e por reduzirem a hermenêutica a uma mera história do pensamento. De acordo com essa perspectiva, a ideia de compreensão foi amplamente interpretada em termos psicológicos. Assim, era de se esperar que os quadros de referência teórico-metodológicos predominantes no pós-Guerra obliterassem, de uma maneira geral, as pretensões de uma teoria social fundamentada na "compreensão". Contudo, o renascimento da filosofia analítica anglo-saxônica (em boa medida instigada pelo pensamento wittgensteiniano) e dos movimentos sociológicos fundamentados no pragmatismo e na fenomenologia recolocou em outras bases a ideia de compreensão como tema central na teoria social. Tratam-se de concepções teóricas que, entre outros aspectos, evidenciam problemas relacionados com a significação na vida cotidiana, com a linguisticidade da compreensão e com as condições de possibilidade do conhecimento sobre a ação social (Alves, 2010).

A imagem de que o campo próprio da compreensão é a subjetividade está associada às concepções hermenêuticas que estiveram subjacentes às discussões sobre o significado da compreensão. É bem verdade que a hermenêutica quando se desregionalizou, deixando de ser uma interpretação do discurso filológico, bíblico ou jurídico para se definir como uma teoria geral da interpretação, tomou como um dos temas básico de investigação a relação entre vida e obra. Para os teóricos das "ciências do espírito" (Geisteswissenschaften), o "problema da hermenêutica" resumia-se na questão de como compreender a vida que se expressa e se fixa em uma obra. Nesse contexto, Dilthey assumiu uma posição significativa ao tentar estabelecer uma síntese dos princípios da ciência com os da "filosofia da vida", proporcionando um importante modelo para as subsequentes abordagens relativas à compreensão da ação social. Para esse autor, se a vida está na origem da obra, a recuperação desta pela interpretação deve procurar reconstituir o caminho da criação.

Preocupado com a "experiência vivida", Dilthey atribuiu ao intérprete a tarefa de buscar na obra os traços do que foi a vida. Para garantir objetividade na realização dessa tarefa (ou seja, permitir ao intérprete penetrar imaginativamente na mente do autor), 
procurou prover as ciências humanas de um método específico que fosse tão válido e rigoroso quanto o das ciências naturais. Nesse aspecto, Dilthey e seus seguidores, ao buscarem uma "sólida" base científica para a análise de "significações" ou investigação do sentido, terminaram por reduzir a hermenêutica a uma questão epistemológica e metodológica. Comentando sobre a obra de Dilthey, Bleicher observa:

A necessidade de procurar fazer uma crítica da "razão histórica" para completar a Crítica da razão pura de Kant resultou de tensões inerentes à filosofia moderna que, no seu desenvolvimento, deu origem a um dualismo que surge ao nível da filosofia e da ciência, da metafísica e da epistemologia, da crença e do conhecimento, do logos e do ethos, da razão pura e da prática, da filosofia sistemática e da filosofia da vida, da lógica e da história (Bleicher, 1992: 35).

Os pressupostos iluministas e românticos que estão presentes na teoria hermenêutica de base diltheyniana expressam um conjunto de polaridades (como razão/vida, sujeito/objeto) que estão subjacentes a muitas teorias sociais do século XX. Quais são esses pressupostos? Em que sentido pode-se dizer que o lluminismo e o Romantismo estabeleceram as bases para uma discussão sobre a objetividade e a subjetividade? O presente artigo objetiva discutir essas questões. Mais especificamente, procura caracterizar alguns dos princípios que estão subjacentes na concepção usual de subjetividade (e, consequentemente, de objetividade) e discutir como a hermenêutica contemporânea (de base gadameriana) propõe superar a oposição subjetivo-objetivo. Por último, o presente texto examina brevemente as consequências ou reflexos deste debate no âmbito da teoria social.

\section{Objetividade e subjetividade na tradição iluminista}

O lluminismo foi um instante de confluência e ruptura de ideias desencadeadas pelo Renascimento. Para Hauser (1995: 597), o lluminismo foi "a escola primária política da moderna burguesia", e com isso esboçou, por um lado, dissidências significativas com a época anterior e, por outro, anunciou o advento do Romantismo, antecipando movimentos intelectuais posteriores.

O "Século das Luzes" (XVIII), cujo grande símbolo foi a Enciclopédia (1751-1772) concebida por Diderot e d'Alembert, exaltou, guardando a singularidade de cada nação, o antropocentrismo, a ânsia de universalidade, o amor do natural, a autoconfiança na razão e na ideia de que o Universo é regido por leis imutáveis e harmonicamente ordenadas. Mas é importante chamar atenção que, embora "racionalista" e dotado de um "espírito sistemático", o lluminismo já anunciava uma certa descrença na unidade e invariabilidade da razão. ${ }^{2}$ A concepção de razão do "século da filosofia" esbarra na imprevisibilidade da natureza humana. Conforme observa Antonio Candido,
2. Vico (1668-

1744), ao argumentar contra o cartesianismo defende certa liberdade de criação para dar expressão à fantasia; Hume (1711-1776), em oposição às tendências abstratizantes do racionalismo francês, defende a relatividade do gosto, entendido como algo dotado de subjetividade; Pope (1688-1744) defende o princípio da naturalidade ao admirar no índio sua disponibilidade intuitiva para compreensão dos fenômenos naturais; Gravina (1664-1718) aplaude a sabedoria popular. Nesse aspecto, JeanFrançois de la Harpe (1739-1803) chegará a criticar o epíteto atribuído ao século XVIII, como "século filosófico", ao dizer que "só poderia sêlo, talvez, na medida que fosse notável pelos progressos sensíveis da Razão, aplicada a todos os objetos que é capaz de aperfeiçoar, ou pelo menos melhorar, para a glória e a felicidade da espécie humana" (apud Mongelli, 1992: 134). 
[...] à claridade seca do universo cartesiano ia sucedendo uma penumbrosa magia, mal disfarçada por todo o aparato científico da filosofia, propiciando interesse bem mais acentuado por aquelas zonas imprecisas que a psicologia preferia banir, couraçando-se na distribuição dos fatos da alma entre entendimento e vontade (Candido 1969: 58).

O Iluminismo deu tanto continuidade como rompimento com a tradição intelectual do século anterior. Esse movimento duplo é visível na ideia de "progresso" espiritual - entendida como ampliação qualitativa do saber - que está presente em todo o século XVIII. Para os filósofos desse período, a ideia de progresso estava associada à concepção de que o homem deve tomar diversas direções para decifrar a totalidade da realidade (incluindo o mundo social), buscando na multiplicidade e variedade dos âmbitos em que se move uma essência homogênea e unitariamente informadora (Cassirer, 1943). Tal essência é alcançada pela razão. A primazia da razão como vetor para alcançar a essência é partilhada, de maneira geral, pelos pensadores dos séculos XVII e XVIII. Contudo, há uma diferença significativa na forma como no século XVIII o Iluminismo realiza esse empreendimento. O racionalismo do século anterior caracterizou-se pela construção de sistemas abstratos de explicação da realidade a partir de ideias inatas. Nessa perspectiva, a razão foi concebida como ferramenta analítica a operar dedutivamente. No lluminismo, já não se admite a premissa de que o pensamento alcança um verdadeiro saber partindo de um ente supremo e de uma certeza fundamental através da qual, mediante um rigoroso encadeamento de dedução sistemática, chega-se a novos princípios. Em seu Tratado dos sistemas (1749), Condillac (1984), um dos principais representantes da filosofia francesa do século XVIII, observa que os sistemas abstratos são compostos por definições frívolas, de uma fecundidade aparente e inútil.

Ao se oporem à construção de grandes "sistemas" filosóficos e tentarem empreender uma síntese do empirismo e do racionalismo, os filósofos iluministas consideram que a realidade objetiva é o ponto de partida de todo o pensamento e a razão uma força aliada à experiência sensível e à observação. Nesse sentido, argumentam que não há oposição intrínseca entre "experiência" e "pensamento". Kant, nesse aspecto, é ilustrativo. Ao colocar a ciência como um empreendimento no qual o homem só conhece as coisas tal como elas se lhe aparecem, a concepção kantiana é paradigmática, não apenas dentro do contexto filosófico do lluminismo, mas também para algumas das principais vertentes da epistemologia e da teoria social moderna.

Na introdução à Crítica da razão pura, publicado em 1781, Kant observa:

Não resta dúvida de que todo o nosso conhecimento começa pela experiência; efetivamente, que outra coisa poderia despertar e pôr em ação a nossa capacidade de conhecer senão os objetos que 
afetam os sentidos e que, por um lado, originam por si mesmos as representações e, por outro lado, põem em movimento a nossa faculdade intelectual e levam-na a compará-las, ligá-las ou separá-las, transformando assim a matéria bruta das impressões sensíveis num conhecimento que se denomina experiência? [...] Se, porém, todo o conhecimento se inicia com a experiência, isso não prova que todo ele derive da experiência. Pois bem poderia o nosso próprio conhecimento por experiência ser composto do que recebemos através das impressões sensíveis e daquilo que a nossa própria capacidade de conhecer (apenas posta em ação por impressões sensíveis) produz por si mesma, acréscimo esse que não distinguimos dessa matéria-prima, enquanto a nossa atenção não despertar por um longo exercício que nos torne aptos a separá-los (Kant, 1989: 36).

Em sua crítica à "metafísica dogmática", Kant parte do pressuposto de que é na determinação puramente empírica da experiência que surge a objetividade, pois é nela "que justamente se combinam os dados confusos e mutáveis da sensibilidade com o que por si mesma produz a nossa faculdade de conhecer" (Silva, 1995: 16). Em outras palavras, a verdade e a libertação dos preconceitos - princípios da Aufklärung - só são possíveis se a experiência humana, em si mesma caótica ou preconceitual, for objetivada, isto é, configurada aprioristicamente através das categorias do entendimento humano, pelas estruturas universais de uma subjetividade anônima e transcendental. ${ }^{3}$ Assim, ao afirmar que as formas a priori da razão são independentes da experiência, Kant sustentou a ideia de que a razão fundamenta a possibilidade da experiência, condiciona-a e determina os limites de sua objetividade. Dessa forma, a concepção empirista da imediaticidade das percepções humanas singulares é errônea, pois elas já são antecipadamente mediadas pelo próprio projeto da razão que as experimenta.

O vínculo entre teoria e prática, entre as formas a priori da razão e a experiência, é visto pelos iluministas como condição necessária para a explicação da ordem e legalidade absoluta da realidade. Como é do conhecimento geral, tal vínculo é pautado no modelo epistemológico e metodológico estabelecido pelas ciências naturais (físico-matemáticas) da época. Na busca dessa fundamentação, o lluminismo instaura uma nova lógica: a "lógica dos fatos". Como observa Cassirer,

o espírito tem que abandonar-se à plenitude dos fenômenos e regular-se incessantemente por eles, porque deve ser seguro e, longe de se perder naquela plenitude, encontrar nela sua própria verdade e medida (Cassirer 1943: 23).

Assim, ao admitir que a verdadeira explicação da realidade pressupõe uma lógica fundamentada pelo método da ciências físico-matemáticas, os iluministas, a princípio, não negam a complexidade e diversidade dos fenômenos naturais e socioculturais

3. O "enciclopedista" Jaucourt, por exemplo, afirma que os preconceitos são como fantasmagorias "que um gênio maligno tivesse enviado à Terra para torturar os homens: são uma espécie de enfermidade contagiosa, que como toda as epidemias, ataca principalmente o vulgo, as mulheres, as crianças e os velhos, e que só retrocede ante o poder da sabedoria e da razão" (apud Lenk, 1974: 53). 
4. Esse sujeito é interpretado à luz do individualismo filosófico desenvolvido, em seus fundamentos, por Leibniz. Com base nos princípios leibnizianos, a subjetividade é identificada com a ideia de "mônada", isso é, substâncias, realidades individuais ou individualidades independentes uma das outras, dotadas de dinamismo interno, fechadas em si mesmas, e que não possuem "janelas" através das quais as coisas possam entrar ou sair. Assim, a subjetividade é vista como individualidade autoinstituída mas, ao mesmo tempo, submetida a uma ordem interna constituída por sua própria determinação. 0 indivíduo basta por si mesmo, é um mundo à parte, regulado por sua própria natureza. existentes no mundo. Contudo, com o objetivo de conhecê-los seguramente, os reduzem a um único processo discursivo que busca a uniformidade, a causalidade, a homogeneidade e o determinismo universal. Nesse aspecto, Ortega y Gasset (1947) chama atenção que o racionalismo, para salvar a "verdade objetiva", renuncia à vida. Argumenta que, sendo a verdade uma, absoluta e invariável, não pode ser atribuída a pessoas individuais, mundanizadas e passíveis de corrupção. Assim, haveria de supor a existência de um sujeito abstrato comum a todos os homens. Para Ortega (1947: 159), "el racionalismo es antihistórico".

Ao cultivar a ideia de uma regularidade constante e involuntária subjacente aos fenômenos, que serve de base para a admissão de uma "racionalidade" interna à própria realidade, a explicação do social pelos pressupostos iluministas tende a reduzir a variedade observada no mundo empírico à uniformidade, a um esquema regular e fixo, impondo no processo social um ideal de constância, de generalidade e classificação produzidas pela razão. Como diz Eduardo Nicol (1960: 76), “o ideal de história é deixar de ser histórica. A regularidade do princípio causal suprime necessariamente toda inovação". O lluminismo, embora enuncie diferenças nas ontologias regionais, termina por igualar, em relação ao ato e à estrutura gnoseológicos (o modo de conhecer e a estrutura do conhecimento), o objeto cultural e o natural.

A razão, para os filósofos das luzes, não elimina a ideia da individualidade. Pelo contrário. O século XVIII afirma a soberania do sujeito da razão. ${ }^{4}$ Essa ideia de autossuficiência do homem, uma espécie de humanismo laico pregado principalmente pelos ingleses e franceses, encontra em Robinson Crusoe (1719), de Daniel Defoe, um excelente exemplo: um homem, perdido na solidão selvagem de uma ilha desabitada, é forçado a recriar, como autodidata, sua vida. Tomado por uma "resolução destemida", consciente de suas possibilidades e de seu destino, artífice exclusivo de seu mundo, metódico e trabalhador infatigável, Crusoe transforma, pela experiência e pela razão, seus 28 anos de solidão em triunfo. O herói de Defoe é, no fundo, uma imagem abstrata do homem, um ser individualista em todos os seus sentidos, econômico, religioso, moral.

Os pressupostos iluministas fundamentam, em grande medida, as teorias sociais que prevaleceram após a Segunda Guerra. Em termos gerais, essas teorias partem de um princípio: para se adquirir o status científico é necessário desenvolver um conhecimento capaz de apreender uma realidade em si mesma. O que se espera da "imaginação sociológica" é que ela possa apreender estruturas, sistemas de relações. Em síntese, regularidades (independentes das vontades ou consciências individuais).

Nessa perspectiva, a possibilidade de se obter um conhecimento "objetivo" do mundo social está embasada em dois grandes pressupostos teórico-metodológicos. O 
primeiro é o de que a ciência deve ser essencialmente analítica e abstrata, o que significa dizer que ela constrói a realidade por meio de símbolos conceituais que não devem ser confundidos com a "realidade concreta". Whitehead (2006) observa que tal concepção parte do seguinte princípio: os elementos de um todo, que podem dele ser isolados através de uma análise, não podem ser igualados com as ocorrências concretas. Os símbolos conceituais são elaborados, portanto, ao selecionarmos da realidade certos traços, certos elementos que se tornam privilegiados para estruturar nossa percepção e nosso conhecimento das coisas. Nesse sentido, a teoria é um sistema integrado de conceitos dotado de uma estrutura lógica determinada. Em outras palavras, um quadro de referência teórico é uma coleção sistematizada de proposições relativas a domínios conexos - mas diferenciados - entre as quais é possível se estabelecer (com "precisão objetiva") uma série de equivalências e diferenças. Assim, embora abstrata, a teoria é objetiva no sentido que procura dar respostas a questões relevantes estabelecidas pelos problemas construídos pelo observador. O segundo pressuposto - decorrência direta do primeiro - parte da premissa de que, para ser de algum modo significativo, um conceito científico deve estar em condições de relacionar-se à experiência, o que será o teste de sua verdade. Assim, a significação de um conceito só pode ser concebida em termos daquelas experiências que o teste possibilita. Nessa perspectiva, para que o conceito possa atender a esse pré-requisito, é necessário que ele seja submetido a "operações lógicas" relativas aos objetos da experiência.

Em síntese, a tese que está subjacente a esses dois pressupostos é a de que o entendimento da realidade última de um fato social é sustentado por configurações teórico-metodológicas. Ou seja, se a ideia de ciência parte da convicção da existência de uma "ordem das coisas" ou "senso de ordem", como se o mundo fosse dotado de um "enredo próprio", no dizer de Whitehead (2006: 16), então pode-se concluir que só apreendemos objetivamente algo quando apreendemos a "ordem das coisas". Trata-se, portanto, de uma apreensão fundamentada, em última instância, em princípios cognitivos (modelos analíticos) que guiam o conhecimento. Nesse sentido, a abstração é o recurso explicativo último dos fenômenos sociais. Com isso, a imaginação sociológica é catapultada para uma dimensão arquimediana - um ponto colocado fora da experiência (da percepção imediata dos fenômenos) a partir do qual é possível analisar o mundo social. Não é por acaso que a matemática, com seus artifícios lógicos, é um exemplo de procedimento correto, científico, objetivo. A matemática - libertando "o homem dos grilhões da experiência terrestre", no dizer de Hannah Arendt (2000: 277) - cria uma linguagem que reduz os dados sensoriais e as ações humanas a símbolos. Permite "medir" acontecimentos e transforma a multiplicidade das coisas, por mais desordenada, incoerente e confusa que sejam, em certos padrões e configurações. 
5. Ao analisar esse movimento, Volobuef (1999: 12) observa que houve "as lágrimas, sem dúvida, mas também o grito por justiça; houve o gesto retrógrado, mas também a diligência inovadora; houve o espírito voltado para o passado, mas também o olhar em busca do futuro".

\section{Um exemplo} significativo para essa concepção pode ser encontrado no poema "O que é a vida dos homens?..." ("Was ist der

Menschen Leben?..."), de Hölderlin (1991: 456-457):

"O que é a vida dos homens?

Imagem da divindade. / Enquanto sob o céu erram os seres terrenos todos, eles / veem-no. Mas como se lessem / num escrito, os homens imitam a infinidade / e a riqueza. E é o céu simples / rico então? Como flores são em verdade / nuvens argênteas. Mas de lá chove / o orvalho e o relâmpago. Quando porém / se apaga o azul simples, parece / o baço do céu, que se assemelha ao mármore, como minério / anúncio de riqueza".

Novalis (1988: 87), por sua vez, dirá: "Estamos em relação com todas as partes do Universo - Assim como com o futuro e a Antiguidade".

7. Novalis escreve (1988: 45): "A sede da alma é ali onde o mundo interior e o

\section{Objetividade e subjetividade na tradição romântica}

A concepção de realidade objetiva, proposta pelos iluministas, assumirá outra perspectiva no movimento romântico. Ao procurar fundamentar o "mundo do espírito", ao colocar a problemática da historicidade e ao discutir as aporias do relativismo e do particularismo, esse movimento põe em questão alguns dos principais pressupostos do período anterior. Ao se contrapor à "filosofia da razão", o Romantismo defende a "filosofia da vida". Contudo, é sempre bom lembrar que o Romantismo, apesar de seu caráter revolucionário, é também continuação e alargamento do pensamento iluminista. Mesmo admitindo o poder criador do "Eu", enfatizando a subjetividade, o Romantismo continua preocupado com uma fundamentação "objetiva" das ações humanas, com uma reconstrução metódica do "mundo do espírito" construída dentro dos parâmetros de exatidão e certeza científica. Mantém, nesse sentido, o pathos vitorioso da ciência desencadeado pelo lluminismo.

O Romantismo - assim como o lluminismo - é um movimento filosófico, literário e artístico extremamente complexo, apresentando grande diversidade de tendências e se ramificando nas mais variadas direções. ${ }^{5}$ Em sua rebeldia contra o lluminismo, em sua ânsia de liberdade espiritual, em sua sede de infinito, o Romantismo tornou-se múltiplo, quase impossível de ser fixado em um ideário imutável. Contudo, é possível perceber alguns traços básicos, recorrentes. Com a devida cautela, pode-se dizer que domina entre os românticos um sentimento de totalidade que advém de uma concepção da natureza como grande organismo que se reflete de alguma forma no homem, assim como este se reflete no todo. ${ }^{6} \mathrm{~A}$ "ansiedade" ("Sehnsucht", "longing", "sensiblerie") é o "estado de espírito" romântico, um desejo irrealizável porque indefinível, sentido como inextinguível, 7 de "unir-se ao grandioso". ${ }^{8}$ Para Weiskel (1994), essa é a matéria-prima do "espírito romântico".

Hölderlin, em seu ensaio "O devir no perecer" (1994: 74) resume essa concepção:

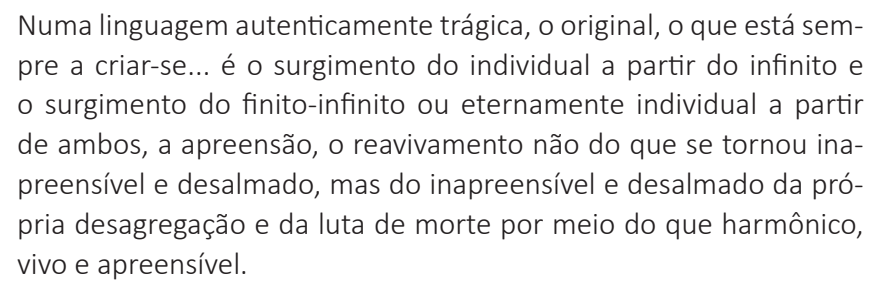

Dois temas são centrais para o Romantismo: a atividade criadora do espírito e a historicidade.

Ao consagrar as forças irracionais da vida e o arbítrio do "gênio", o Romantismo tende a opor o sentimentalismo ao racionalismo, a imaginação à especulação. Para esse 
movimento, o polo de atenção é o indivíduo, o "Eu", matriz do ato criador. "A 'pessoa' no Romantismo", resume Sciacca (1966: 12),

\begin{abstract}
não é criatura, é princípio de si mesma; não é liberdade em relação a uma lei transcendente que a disciplina, mas é "liberdade de natureza" ou espontaneidade. Similarmente não é cristã a interioridade romântica; é subjetividade da verdade, imanência dela ao sujeito, que "tudo cria"; é um desenvolvimento e também uma "interpretação" da "revolução copernicana" de Kant, consoante o qual tudo gravita em torno do sujeito (o ser tende a resolver-se no pensamento).
\end{abstract}

Em vários aspectos, a concepção de Fichte do Eu puro, da produtividade do Eu ativo (Ego), entendido como intuição pura que se autocria e, autocriando-se, cria toda a realidade, resume o pensamento romântico sobre a individualidade.

Conforme já observado, este Eu criador do Romantismo está remetido a uma totalidade. O Romantismo rebelou-se contra o domínio da razão universal abraçada pelo Iluminismo, pregando a verdade da tradição, o retorno ao mythos. Para os românticos, a relação entre individualidade e totalidade realiza-se na história, na "consciência coletiva dos povos". Nesse sentido, pressupõe uma perspectiva histórica, a qual atribui à tradição de cada época o seu próprio valor e perfeição. A história é vista como conjunto de manifestações individuais de ação que se substancializa em um "espírito do povo". O ideal romântico era reviver o passado em sua própria posição histórica, na individualidade dos produtos da cultura humana. Assim, o Romantismo preocupou-se em distinguir o conhecimento da natureza do conhecimento dos objetos histórico-sociais.

Nesse aspecto, o Romantismo inicia uma hermenêutica da historicidade, cuja figura emblemática é Friedrich Schleiermacher (1768-1834) e seus seguidores, August Boeckh e Gustav Droysen. ${ }^{9}$ Influenciado pela tradição exegética da teologia protestante, pela filologia clássica do século XVIII e por uma exigência filosófica de extração kantiana, Schleiermacher procurou analisar as condições gerais sob as quais ocorre a compreensão do texto, fornecendo métodos para o processo interpretativo. A hermenêutica transformou-se, portanto, em compreensão geral da estrutura da interpretação que caracteriza o conhecimento enquanto tal (Schleiermacher, 1999). Sob essa perspectiva, a recuperação objetiva de um discurso consiste tanto na reativação de sua significância, a partir das regras sintático-semânticas da língua (interpretação gramatical), quanto na recuperação do "momento subjetivo do discurso" (interpretação psicológica), isso é, na compreensão do modo pelo qual o "autor opera na linguagem" e na "identificação empática" com o autor. Assim, a compreensão do discurso alheio, a apreensão do pensamento do outro, se realiza através do entrecruzamento da "totalidade da linguagem" e da "totalidade da vida do autor". mundo exterior se tocam. Onde eles se interpenetram - está ela em cada ponto de interpenetração".

8. Weiskel (1994) considera esta a matéria-prima do "espírito romântico".

9. Para Boeckh, uma obra só pode ser entendida em termos de condições objetivas (interpretação gramatical do significado literal do texto) e subjetivas (interpretação histórica em relação à situação objetiva do autor) do que é comunicado. Droysen, hostil às tendências positivistas do século XIX, estabeleceu (antes de Dilthey) como premissa da teoria da interpretação a separação entre natureza (Natur) e mente (Geist) e a unidade fundamental da natureza humana. 
Ao analisar as condições de possibilidade do conhecimento histórico, o Romantismo estabeleceu as bases para a gênese do movimento filosófico que surge no final do século XIX: o historicismo. O historicismo estendeu o âmbito da crítica kantiana ao fenômeno histórico-social, mas com uma diferença fundamental: o sujeito do conhecimento já não é o sujeito transcendental, e sim os homens concretos, historicamente determinados. No projeto de construir uma "crítica da razão histórica", os "neokantianos" (como Dilthey) sustentaram a ideia de que há diferenças gnosiológicas significativas entre as ciências naturais e as ciências do espírito, tendo em vista a diferença entre os seus objetos de estudo. Para Dilthey (2010), a compreensão (o Verstehen) do objeto das ciências do espírito é dada pela observação interna dos fenômenos humanos, pela experiência vivida (Erlebnis). A corrente da vida (Erleben) realiza-se em complexos de objetivações cujo significado é entendido graças ao esforço de compreensão. No entendimento - que é o "encontro do Eu no tu" - o "sujeito do saber é idêntico ao seu objeto". Ou seja, as significações das ações humanas têm uma estrutura temporal ideal, que por si mesma impõe-se, solicitando do intérprete uma "experiência intersubjetiva de solidariedade no sentido". Dilthey, portanto, efetua uma hermenêutica da compreensão fundamentada no pressuposto de que a compreensão penetra, recupera e reconstrói o objeto histórico no todo originalmente vivido que subjaz ao conjunto das exteriorizações de uma determinada época histórica. Assim, Dilthey busca ao mesmo tempo a compreensão do gênio artístico e da verdade revelada da obra de arte e pretende assegurar-se de que este empreendimento pode ser levado a cabo pelo uso da razão metódica, garantia da objetividade e universalidade da interpretação.

\section{Reconsiderando o embate entre lluminismo e Romantismo}

A tensão entre lluminismo e Romantismo desdobra-se em uma série de oposições, algumas das quais bastante relevantes na história das ciências sociais. As oposições entre razão e emoção, liberdade da razão e autoridade da tradição repercutem nas ciências sociais e se traduzem em diversas polaridades: distância versus envolvimento; preocupação com o desvelamento de essências versus preocupação com fluxo da vida; proposta de classificação do mundo através de categorias abstratas versus proposta de descrição de processos singulares; ênfase no geral versus ênfase no particular; na estrutura versus na ação; na sociedade versus no indivíduo; na objetividade versus na subjetividade; enfim, universalismo versus singularismo, holismo versus individualismo. Um ponto importante em relação a essas tensões diz respeito ao questionamento de serem usualmente sustentadas pelas ciências sociais.

Para analisar essa questão, voltemos a nossa atenção mais uma vez para o lluminismo e o Romantismo, principalmente no que se refere a determinados pontos em comuns 
entre essas duas correntes de pensamentos. Aqui recorremos fundamentalmente a algumas observações de Hans-Georg Gadamer.

Conforme já observado acima, uma das áreas de oposição entre lluminismo e Romantismo diz respeito ao valor da tradição. O lluminismo sujeita a tradição aos critérios universais da razão e, contra as restrições e os preconceitos impostos pela tradição, prega a liberdade da razão. Assim a proposta de ciência que nasce do lluminismo está pautada em um critério de objetividade que é fruto da aplicação livre da razão sobre o mundo que se trata de conhecer, isto é de o decompor em um conjunto de leis gerais ou relações típicas, a partir das quais se possa fazer previsões mais ou menos seguras. Nesse caso, transfere-se para as ciências humanas os procedimentos cognitivos das ciências da natureza. Por sua vez, o Romantismo reage ao movimento devastador da razão iluminista, pregando o retorno à tradição, a verdade do mythos em oposição à verdade do logos. Propõe que o investigador se transponha para o mundo dos sujeitos investigados de modo a recuperar a unidade ou o sentido interno das mais variadas formas de alteridade. Torna-se, assim, a imagem refratada do lluminismo, defendendo a sabedoria do passado, a consciência mítica que vigora em um tempo primevo, a autenticidade e beleza do antigo. Reverte o valor que o lluminismo confere a estes termos, mas não os contesta. A fraqueza da crítica romântica está justamente no fato de que compartilha dos pressupostos do lluminismo: a tradição que os românticos abraçam é um fato objetivo que os iluministas rejeitam, apenas com o sinal invertido.

A hermenêutica romântica oferece um exemplo interessante do enredamento do Romantismo nas malhas do lluminismo. Aí a questão que permeia todas as ciências humanas diz respeito à possibilidade de se ascender ao universo interior do outro, a alteridade, o passado. Guiado por um ideal de conhecer e tornar inteligíveis as tradições passadas em seus próprios termos, o movimento romântico transformou a tradição em objeto de investigação científica - mostrando assim que as tradições que não fazem sentido para o presente podem ser compreendidas "historicamente", em termos de uma visão de coisas do passado. Essa atitude permite que as épocas antigas sejam estudadas em sua "inteireza e lógica interna". Compreender o passado é reconstituir o ponto de vista da época e, assim, recuperá-la objetivamente para o presente. Em outras palavras, ao valorizar a tradição, a alteridade, o Romantismo pretende desenvolver uma atitude de escutar a "voz do outro" (que para as ciências sociais corresponde o sistema de crenças e práticas presentes nos diferentes "modos de vida"). Pretende, contudo, reconstituir o "outro" como uma totalidade coerente através de rigorosos procedimentos cognitivos. Nessa perspectiva, a hermenêutica é pensada e desenvolvida como método para compreender a alteridade. Sua aplicação deve conduzir a uma objetividade: o resultado do empreendimento hermenêutico deve ser - conforme afirmou Schleiermacher - compreender um autor melhor do que ele mesmo se compreende. Fazer isso é reconstituir o percurso mesmo pelo qual a obra foi criada 
e assim elucidar sentidos que escaparam à reflexão do próprio autor. Nesse ponto, a proposta da hermenêutica romântica desemboca claramente na proposta iluminista: ambas comungam do mesmo ideal de objetividade. Mais especificamente, ambas não levam em devida consideração o processo dinâmico, histórico, do conhecimento. Ou seja, lluminismo e Romantismo aproximam-se justamente naquilo que ambos negligenciam: a natureza essencialmente histórica do conhecimento e, portanto, o papel da tradição enquanto horizonte em que se processa todo conhecimento.

Essa questão parece-nos fundamental e importa, portanto, determo-nos um pouco mais nas implicações de se considerar a natureza essencialmente histórica do conhecimento sobre os fenômenos humanos.

Segundo Gadamer, as ciências sociais têm à sua frente uma tarefa que é essencialmente hermenêutica: envolvem a compreensão de contextos de vida muitas vezes estranhos ao intérprete e assim colocam o problema da mediação entre pontos de vista ou perspectivas distintas: aquela em que se situa o investigador e aquela que caracteriza as ações, eventos e fatos que se trata de interpretar. Na tradição hermenêutica, esta mediação é resolvida no já bastante conhecido círculo hermenêutico. A ideia é de que o entendimento é alcançado através de um movimento que vai do todo, apreendido enquanto antecipação, à parte, e de volta ao todo: "a tarefa é expandir a unidade do sentido compreendido centrifugalmente" (Gadamer, 1997: 291). Para a hermenêutica romântica, este movimento da interpretação seria concluído quando estivesse plenamente reconstituído o processo de criação da obra, no caso da interpretação de textos, ou o ponto de vista da época, no caso da análise histórica. O problema da compreensão é um problema epistemológico.

Ao procurar situar a compreensão em solo ontológico, Gadamer recorre a Heidegger para repensar a ideia de círculo hermenêutico. Antes que um método das ciências humanas, a compreensão é uma estrutura essencial do ser-no-mundo ou dasein. Isso significa que a própria vida cotidiana envolve o movimento incessante da compreensão, não enquanto realização intelectual, mas como referência contínua da prática a um horizonte não tematizado de sentido. Cada outro a quem nos dirigimos e que nos confronta, bem como cada instrumento a que recorremos em nossa prática, está referido a um lugar - a uma teia de relações que nos conecta a outras pessoas e instrumentos. Não nos defrontamos com coisas que significamos, mas com contextos de sentido nos quais nós mesmos estamos implicados. Toda prática singular remete a esses contextos e é assim também movimento da compreensão que elabora o particular a partir do todo. Em outras palavras, habitamos o mundo, portanto, sempre nos movemos em um campo de compreensão prévia. As ciências humanas constituem uma elaboração especial do que constitui a própria estrutura da experiência humana no mundo. 
A retomada do problema da compreensão está ligada a uma redefinição e, conforme veremos adiante, a uma reabilitação da tradição no processo de objetivação das ciências humanas. Pensada a partir da noção heideggeriana de mundo, a tradição aparece como condição de todo conhecimento, como força que põe em ação o conhecimento. Para Heidegger, o mundo não é a soma das coisas que existem, mas a condição para que as coisas apareçam; é uma a rede de remissões que liga pessoas, pessoas e instrumentos, propósitos práticos, contextos de convivência e ação. É porque habitamos o mundo que podemos constituir sujeitos e objetos como entidades separadas. Não podemos descrever o mundo tentando enumerar as entidades que o formam; em um processo desse tipo o mundo seria ignorado, pois ele é justamente aquilo que é pressuposto em todo o ato de conhecer uma entidade (Heidegger, 1997: 104). Esta ideia não aponta simplesmente para uma relação entre o sujeito e objeto, mas para o solo mais originário sobre o qual se assentam as perspectivas do subjetivo e objetivo.

A partir da ideia de um enraizamento fundamental do ser no mundo, a compreensão que almejam as ciências humanas não pode ser reduzida a uma tentativa de acesso à interioridade do sujeito/autor. A subjetividade precisa ser colocada em sua devida dimensão e, com ela, também a objetividade, que nada mais é que sua contrapartida necessária. Vejamos primeiro o que isso implica para o entendimento da experiência. Conforme observa Dreyfus (1996), a crítica heideggeriana ao modelo tradicional de interpretação do ser-no-mundo a partir das categorias de sujeito e objeto enfatiza um envolvimento mais fundamental das pessoas entre si e com as diversas entidades que povoam seu mundo, do que a relação pressuposta na ideia de encontro entre uma interioridade autorreferente e objetos exteriores. Este envolvimento é, antes de tudo, um engajamento prático no mundo: não requer ordinariamente o posicionamento de um sujeito que constitui e destaca objetos. Do ponto de vista da teoria da ação isso quer dizer que a situação é um campo de envolvimentos - e não um espaço neutro de objetos que o ator deve primeiro conhecer para instrumentalizar a seu serviço. Da mesma forma, conduz à ideia de que os fins da ação não são formulações abstratas que é preciso dominar intelectualmente para depois pôr em execução, apenas em condições especiais se destacam enquanto planos refletidos.

Assim, argumenta Gadamer, uma perspectiva subjetivista nas ciências sociais, que toma como o ponto de partida a interiorização das vivências, não pode construir a ponte para as realidades históricas, porque estas são sempre determinantes prévios de toda vivência. As interpretações que articulamos acerca de nós mesmos e de nossas atividades estão apoiadas em um conjunto de práticas sociais que já contêm em si uma interpretação prévia. Antes mesmo que nos compreendamos na autorreflexão, já estamos nos compreendendo de modo autoevidente (não reflexivo) na família, no Estado, na sociedade em que vivemos. Assim, o locus do sentido não é 
a interioridade, mas o mundo público da convivência. "A autorreflexão do indivíduo não é mais que uma centelha na corrente cerrada da vida histórica", observa Gadamer (1997: 416).

Se o sentido da ação não reside nas intenções, nos planos e motivos de seus autores/ sujeitos, será então efeito do mundo, tomado como rede de significação que antecede e circunscreve toda ação? Se é assim, não estão as ciências sociais perfeitamente enquadradas em uma perspectiva estrutural? Aqui estamos frente à questão da relação entre a parte e o todo que recebe elaboração especial na hermenêutica. Gadamer insiste que esta relação não pode ser pensada em termos do universal e particular: a experiência enquanto parte não é simplesmente a instância singular, uma versão empobrecida do todo e que nada diz além do que nele já está dado. A relação entre experiência e vida, ação e mundo, é antes de tudo orgânica. Isso quer dizer que a experiência continuamente redescobre o sentido do todo da vida.

Em toda experiência, o indivíduo se defronta com algo que já é para ele um todo articulado, reconhece uma situação. O reconhecimento funda-se, é claro, na memória. Mas não é simplesmente trazer de novo o passado, enquanto mera reprodução. É o que Gadamer chama de "apresentação": uma contínua reaquisição que tem o caráter de practical enactment. Reconhecer uma situação é já ajustar-se a ela, responder a sua solicitação. O reconhecimento é um evento que tem lugar no fazer, no exercício, no desempenhar. Isso quer dizer que ao mesmo tempo em que a experiência está ligada a uma totalidade prévia de sentido, envolve sempre uma retomada e descoberta do sentido em sua aplicação. Nessa dialética entre reconhecimento e descoberta reside a historicidade interna da experiência, seu caráter de abertura. Gadamer compara a experiência a uma aventura; embora esta interrompa o curso costumeiro das coisas, relaciona-se positiva e costumeiramente com a correlação que interrompe. Assim como uma aventura, a experiência é sempre ao mesmo tempo retomada e também abertura para o novo. Tem-se descrito aqui o próprio círculo hermenêutico: a experiência é uma abertura que se desenrola sobre o solo da pré-compreensão.

\section{Conclusão}

No argumento de Gadamer, a compreensão que tem lugar nas ciências humanas apresenta a estrutura de uma experiência e, portanto, não pode ser pensada como o fez a hermenêutica romântica, ignorando sua historicidade essencial. Compreender um acontecimento passado não é, como pretendeu o historicismo, recuperá-lo em termos do seu próprio horizonte (pois isso é impossível) mas empreender um diálogo com o passado, ou construir uma mediação histórica - e portanto mutável - entre a tradição do intérprete e aquela que busca interpretar. Nesse sentido, Gadamer mostra que: 
[...] a compreensão que se exerce nas ciências do espírito é essencialmente histórica, isto é, que também nelas um texto só é compreendido se for compreendido em cada caso de uma maneira diferente. Este era precisamente o caráter que revestia a missão da hermenêutica histórica, o refletir sobre a relação entre a identidade do assunto comum e a situação mutável, na qual se trata de entendê-lo. [...] a mobilidade histórica da compreensão, relegada a segundo plano pela hermenêutica romântica, representa o verdadeiro centro de um questionamento hermenêutico adequado à consciência histórica (Gadamer, 1997: 461).

A historicidade da compreensão está ligada a seu enraizamento necessário em uma tradição. Se na experiência hermenêutica não há "ponto zero" a partir do qual passa a haver compreensão (pois ela é sempre retomada de algo prévio), também nas ciências sociais não há um ponto fora do mundo ou uma instância metodológica que permita lançar sobre a realidade aquilo que Merleau-Ponty (1994) chama de "olhar de sobrevoo". Nossa compreensão é sempre guiada por uma antecipação de significados - originada da comunalidade que nos liga à tradição. O cientista que julga colocar-se acima dos fatos para compreender a história ou a sociedade, revela não a verdade objetiva que almeja, mas os preconceitos de seu tempo. O problemático nessa concepção não reside apenas em que suas pretensões à objetividade são inatingíveis, mas no que é deixado oculto por trás da consciência metódica de seus procedimentos científicos: os preconceitos de sua orientação. Pois, na medida em que eles permanecem encobertos, escapam à reflexão, à possibilidade de serem postos em questão na própria investigação (Harris, 2007).

O argumento de Gadamer, contudo, não é apenas de que a pura objetividade não é possível, e que, portanto, estamos condenados a viver com a deficiência imposta por nosso enraizamento em uma tradição, em seus preconceitos. De fato, ele procura mostrar a positividade de todo preconceito, termo que adquiriu um sentido negativo no lluminismo com a tentativa de se construir uma ciência sem pressupostos (como já foi mostrado anteriormente). No pensamento do autor, o preconceito ganha o sentido de uma pré-compreensão historicamente transmitida, que ampara e prepara o caminho para outras formas de compreensão. Do ponto de vista da hermenêutica, trata-se de instaurar um diálogo com a tradição do outro em que se leve a sério as pretensões de verdade desta tradição - não no sentido de descrevê-la em seus próprios termos e de supor possível anular-se para produzir tal descrição - mas no sentido de endereçá-la a partir do nosso horizonte, de questioná-la e deixar que ela provoque nossos próprios preconceitos.

A ideia de que a compreensão nas ciências humanas envolve um processo dialógico não supõe que seja alcançado o pleno entendimento dos fenômenos. Ao contrário, enfatiza a relatividade - isto é, historicidade - do conhecimento, seu ancoramento ne- 
cessário em uma tradição. Tampouco instaura a ficção de que as partes deste diálogo detêm as mesmas condições de afirmar seu ponto de vista, ignorando assim as profundas assimetrias de poder que frequentemente separam o universo do investigador e aquele dos sujeitos que investiga. Apenas observa que essas assimetrias se fazem presentes na situação dialógica e são nela retomadas, não podendo ser tratadas como fatores externos que determinam de fora o sentido e a possibilidade da compreensão.

Neste ponto revela-se com mais clareza a posição de Gadamer frente aos problemas constituintes das ciências humanas. Em primeiro lugar, tem-se esboçada a crítica às ciências sociais objetivantes, crítica que Gadamer compartilha com vários teóricos contemporâneos, de posições um tanto diversas, como Habermas, Giddens, Foucault, Bourdieu, Hans Joas. Mais interessante, talvez, encontramos em Gadamer também uma crítica contundente às posições subjetivistas. Esta vai bem além da simples condenação do subjetivismo por sua incapacidade de endereçar as questões centrais colocadas por uma ciência objetivista: revela o solo comum sobre o qual repousam estas duas posições. Conforme vimos, na visão gadameriana, as ciências sociais não podem ser reduzidas a uma simples descrição dos motivos, planos e interpretações dos atores, "a lente da subjetividade - diz ele - é um espelho deformante" (Gadamer, 1997: 416). Entretanto, tampouco devem constituir-se em uma busca por revelar os significados profundos subjacentes às práticas e não imediatamente acessíveis aos atores, seguindo o famoso ditame de Schleiermacher de conhecer o autor melhor que ele mesmo se conhece. Por trás da aparente atitude de resgate do outro, tal pretensão esconde uma postura autoritária, um olhar de cima, que "coopta" e nivela o outro, silenciando-o em sua possibilidade de dizer-nos algo. Se as ciências sociais podem revelar algo que não está contido nas autointerpretações dos agentes não é porque desvendam sentidos ocultos, mas porque o entendimento que produzem envolve o encontro de dois horizontes distintos; é guiado por uma interpelação e se processa no jogo de pergunta e resposta, reconhecimento e descoberta. É justamente na recusa de colocar a si e a sua tradição como partes necessariamente implicadas na dinâmica da compreensão que a perspectiva subjetivista, de filiação romântica, aproxima-se de seu polo oposto. Em ambos os casos, paira a ilusão de uma objetividade, da conquista de um ponto arquimediano a partir do qual a verdade do outro, do texto, da história possa ser finalmente alcançada.

Abstract: The present paper aims to identity some of the presuppositions underlying the idea of understanding in social theory based on hermeneutic-phenomenological approach. It first critically examines the inherited presuppositions of Illuminism and Romanticism regarding subjectivity and objectivity, arguing that they share a same conception of tradition (albeit with an inverted sign). Then, taking Gadamer and Heidegger as an inspiration, it discusses contemporary hermeneutics' project, in order to conclude by observing that understanding has the structure of an experience. From this it follows that understanding in the social sciences is ultimately engaging in a dialogue with the "other" through building a historic - and therefore changing - mediation between two different horizons. Key-words: hermeneutic; understanding; phenomenology; social theory. 


\section{Referências}

ALVES, P. C. A teoria sociológica contemporânea: da superdeterminaçção pela teoria à historicidade. Sociedade e Estado, v. 25, n. 1. Brasília, 2010, p. 15-31.

ARENDT, H. A condição humana. 10. ed. Rio de Janeiro: Forense Universitária, 2009.

ARnove, R. F. Philanthropy and cultural imperialism. Bloomington: Indiana University Press, 1982.

BLEICHER, J. Hermenêutica contemporânea. Lisboa: Edições 70, 1992.

CANDIDO, A. Formação da literatura brasileira, v. 1. São Paulo: Martins, 1969.

CASSIRER, E. Filosofia de la llustración. México: Fondo de Cultura Econômica, 1943.

CondillaC, E. B. Tratado dos sistemas. 3. ed. São Paulo: Abril Cultural, 1984.

Dilthey, W. Select works, v. II. In MAKkreel, R. A.; Frithjof R. (Eds.). Understanding the human world. New Jersey: Princeton University Press, 2010.

DReYfuS, H. L. Ser-en-el-Mundo. Comentario a la división I de Ser y tiempo de Martin Heidegger. Santiago do Chile: Cuatro Vientos Editorial, 1996.

FRIEDRICHS, R. Sociología de la sociología. Buenos Aires: Amorrortu, 2001.

Gadamer, H.-G. Verdade e método. Petrópolis: Vozes, 1997.

HARRIS, M. Ways of knowing (Introduction). New York; Oxford: Berghahn Books, 2007.

HAUSER, A. História social da arte e da literatura. São Paulo: Martins, 1995.

Heidegger, M. Ser e tempo, parte 1. 6. ed. Petrópolis: Vozes, 1997.

HINKLE, R. C. Developments in american sociological theory, 1915-1950. New York: State University of New York, 1994.

Holderlin. Poemas. Lisboa: Relógio d’Água Editores, 1991.

—. Reflexões. Rio de Janeiro: Relume Dumará, 1994.

KANT, I. Crítica da razão pura. 2. ed. Lisboa: Fundação Calouste Gulbenkian, 1989.

LENK, K. El concepto de ideologia. Buenos Aires: Amorrortu, 1974.

Merleau-Ponty, M. Fenomenologia da percepção. São Paulo: Martins Fontes, 1994.

Mongellı, L. M. M. A estética da ilustração. São Paulo: Atlas, 1992. 
NiCOL, E. Historicismo y existencialismo. Madrid: Fondo de Cultura Economica, 1960.

Novalis, F. H. Pólen - fragmentos, diálogos, monólogos. São Paulo: Iluminuras, 1988.

ORTEGA Y GASSET. El tema de nuestro tiempo. In Obras completas, tomo III. Madrid: Revista de Occidente, 1947

PIcó, J. Los años dorados de la sociologia (1945-1975). Madrid: Alianza Editorial, 2003.

PLATT, J. A history of sociological research methods in America 1920-1960. Cambribridge: Cambridge University Press, 1996.

Schleiermacher, F. D. E. Hermenêutica. Arte e técnica da interpretação. Petrópolis: Vozes, 1999.

SCIACCA, M. F. História da filosofia III. Do século XIX aos nossos dias. São Paulo: Mestre Jou, 1966.

SILVA, M. L. F. O preconceito em H.-G. Gadamer: sentido de uma reabilitação. Lisboa: Fundação Calouste Gulbenkian, 1995.

Volobuef, K, Frestas e arestas. A prosa de ficção do Romantismo na Alemanha e no Brasil. São Paulo: Unesp, 1999.

WEISKEL, T. O sublime romântico. Rio de Janeiro: Imago, 1994.

Whitehead, A. N. A ciência e o mundo moderno. São Paulo: Paulus, 2006. 